\title{
Profile of conbercept in the treatment of neovascular age-related macular degeneration
}

\author{
This article was published in the following Dove Press journal: \\ Drug Design, Development and Therapy \\ 22 April 2015 \\ Number of times this article has been viewed
}

\author{
Xinmin Lu' \\ Xiaodong Sun ${ }^{1-3}$ \\ 'Department of Ophthalmology, \\ Shanghai First People's Hospital, \\ School of Medicine, Shanghai Jiao Tong \\ University, Shanghai, People's Republic \\ of China; ${ }^{2}$ Eye Research Institute \\ of Shanghai Jiao Tong University, \\ Shanghai, People's Republic of China; \\ ${ }^{3}$ Shanghai Key Laboratory of Fundus \\ Disease, Shanghai, People's Republic \\ of China
}

\begin{abstract}
In developed countries, age-related macular degeneration (AMD) is the leading cause of irreversible blindness in individuals over the age of 65 years. Vascular endothelial growth factor (VEGF) plays a vital role in the formation of neovascular AMD. VEGF regulates angiogenesis, enhances vascular permeability, and drives the formation of choroidal neovascularization. As a result of the introduction of anti-VEGF drugs, the incidence of blindness from neovascular AMD has greatly reduced. Anti-VEGF drugs are used as a first-line treatment for neovascular AMD. The most recent anti-VEGF drug is conbercept, also named KH902, which was approved for the treatment of neovascular AMD by the China Food and Drug Administration in December 2013. In this review, recent clinical information regarding the use of conbercept to treat neovascular AMD is summarized. Conbercept is a soluble receptor decoy that blocks all isoforms of VEGF-A, VEGF-B, VEGF-C, and PlGF, which has a high binding affinity to VEGF and a long half-life in vitreous. Preclinical studies have demonstrated its anti-angiogenesis activity in both ocular neovascular disease models and tumor models. Clinical trials of conbercept have shown its superior efficacy and safety. Patients respond well even with 3-month treatment intervals following loading doses once a month for 3 months. The potential therapeutic effect of conbercept on the treatment of polypoidal choroidal vasculopathy, a special type of neovascular $\mathrm{AMD}$, is also promising. In summary, conbercept is a new treatment option for ophthalmologists and their patients and may help address the limitations of current anti-VEGF drugs.
\end{abstract}

Keywords: conbercept, KH902, age-related macular degeneration, vascular endothelial growth factor, neovascularization

\section{Introduction}

Aging is a rising concern in the current century, and the number of individuals over the age of 65 years is expected to double between 2005 and 2050. The prevalence of age-related macular degeneration (AMD), as an age-related illness, increases with the aging of the population. AMD is now the leading cause of irreversible blindness in individuals over the age of 65 years in developed countries. ${ }^{1}$ AMD is usually classified into two types: dry AMD and neovascular AMD. Dry AMD accounts for $90 \%$ of affected patients, but most cases of severe central vision loss are due to neovascular AMD, which is characterized by the formation of choroidal neovascularization (CNV) that leads to the accumulation of subretinal and intraretinal fluid, detachment of the retinal pigment epithelium, hemorrhage, and eventual scar formation. ${ }^{2}$

Studies have demonstrated that vascular endothelial growth factor receptor (VEGFR) is the key driver of the formation of CNV. ${ }^{3,4}$ Anti-VEGF drugs are accepted as first-line treatments for neovascular AMD because they prevent the activation of VEGFR and, therefore, arrest choroidal angiogenesis. Anti-VEGF therapy improves the quality of life of patients by restoring their vision. The incidence of severe vision
Department of Ophthalmology, Shanghai First People's Hospital, School of Medicine, Shanghai Jiao Tong University, No. 100 Haining Road, Shanghai, 200080, People's Republic of China

Tel +86 I33 86259752

Email xdsun@sjtu.edu.cn 
loss and blindness in neovascular AMD patients has been reduced by $46 \%$ in the United States of America owing to anti-VEGF therapy. ${ }^{5}$ Similar data were also reported for Denmark $(50 \%)^{6}$ and Israel (51\%). ${ }^{7}$

\section{Current anti-VEGF therapies for neovascular AMD}

Four anti-VEGF drugs have been introduced to ophthalmology since 2004. Pegaptanib (Macugen; Eyetech Pharmaceuticals, Inc., New York, New York, FL, USA) was the first anti-VEGF drug approved for neovascular AMD by the United States Food and Drug Administration (FDA). ${ }^{8}$ Unfortunately, its Phase III trial revealed that, although pegaptanib was capable of preventing or slowing vision loss, no vision improvement was achieved. ${ }^{9}$ Pegaptanib is rarely used in current clinical practice. The widespread use of anti-VEGF therapy started with the induction of the pan-VEGF-A blockers ranibizumab and bevacizumab.

Ranibizumab (Lucentis; Genentech, Inc., South San Francisco, CA, USA and Novartis International AG, Basel, Switzerland) is a humanized monoclonal antibody fragment targeting VEGF that was approved for treating neovascular AMD in 2006 by the FDA, ${ }^{10}$ and bevacizumab (Avastin; Genentech, Inc.) is a full-length, humanized, monoclonal immunoglobulin G1 antibody, with 93\% human and 7\% murine protein, that was initially approved for metastatic colorectal cancer in 2004. ${ }^{11}$ Both drugs block the receptor binding domain of all isoforms of VEGF-A. ${ }^{10}$ The MARINA and ANCHOR trials have shown remarkable vision improvement in response to monthly intravitreal (IVT) treatment with ranibizumab. ${ }^{12,13}$ The CATT and IVAN trials demonstrated that bevacizumab achieves visual improvements comparable to those of ranibizumab. ${ }^{11,13,14}$ IVT injection of ranibizumab or bevacizumab has become the primary treatment for neovascular AMD.

Aflibercept (Eylea; VEGF-Trap Eye; Regeneron, Tarrytown, NY, USA and Bayer AG, Leverkusen, Germany) is a soluble receptor decoy that combines domain 2 of VEGFR-1 and domain 3 of VEGFR-2 with a human immunoglobulin $\mathrm{G}$ (IgG) Fc fragment. ${ }^{15}$ Aflibercept was approved for treating neovascular AMD in 2011. This drug works as a multi-target VEGF family blocker and binds all isoforms of VEGF-A, VEGF-B, and PIGF. ${ }^{15}$ In Phase III VIEW 1 and 2 trials, aflibercept achieved similar visual outcomes as ranibizumab within 95 weeks. Aflibercept is approximately equal to ranibizumab in terms of its efficacy. According to the data for the conducted clinical trials, all three anti-VEGF drugs have similar efficacy when they are used in appropriate treatment regimes.

\section{Limitations of the current anti-VEGF drugs}

Despite the success of anti-VEGF drugs in treating neovascular AMD, modifications are still warranted in several aspects. An analysis of the CATT and IVAN trials showed that monthly administration has a better effect in vision than the pro re nata (PRN) strategy, providing evidence for the bioactivity of anti-VEGF drugs. Additionally, fluctuation in the central retinal thickness (CRT) was observed in groups that received aflibercept injections twice per month, whereas the CRT was stable in the monthly groups. A shorter injection interval leads to a better visual outcome and steady anatomic improvements. If the half-life of anti-VEGF drugs were extended, the therapeutic effect would be extended, reducing the injection times.

There are also concerns regarding patient tolerance for ranibizumab or bevacizumab. ${ }^{16}$ Some patients experience a slow loss of the efficacy of anti-VEGF drugs after repeated administration over time. The rate of tolerance is reported to be $2 \%-10 \% \cdot{ }^{17,18}$ The exact mechanisms of this decline are still obscure. Patients who tolerate ranibizumab or bevacizumab have a therapeutic response when switched from one to the other ${ }^{19}$ or when switched to aflibercept. ${ }^{20}$ Thus, anti-VEGF drugs with different properties or different modes of action are needed.

Polypoidal choroidal vasculopathy (PCV) is a special type of neovascular AMD characterized by the presence of aneurysmal polypoidal lesions in the choroidal vasculature..$^{21,22}$ PCV accounts for $25 \%-50 \%$ of cases of neovascular AMD among Asians. ${ }^{23-25}$ Ranibizumab or bevacizumab can improve the visual acuity (VA) of PCV patients in the 1st year, but their weak effect on polypoidal lesions results in deteriorated vision upon long-term follow-up. ${ }^{26-28}$ Thus, the combination of PDT and an anti-VEGF drug or a new anti-VEGF drug with improved activity against PCV may be warranted.

The treatment of neovascular AMD requires repeated injection and long-term follow-up. Financial burdens for both patients and the medical insurance system accumulate over time. The global neovascular AMD market is estimated at approximately US $\$ 4$ billion a year and is predicted to grow to approximately US $\$ 8$ billion by $2016 .{ }^{29}$ The high cost of anti-VEGF drugs contributes substantially to this huge market. Ranibizumab has the highest price, followed by aflibercept (US\$100 cheaper per dose). In the United States of America, Medicare spent US\$950.8 million on ranibizumab injection in 2012, one of the highest costs for a single item in Medicare plan B. ${ }^{30}$ In countries such as People's Republic of China, payments for ranibizumab are not covered by social medical insurance. Patients must pay the full price, making it difficult for 
some patients to afford regular treatments. Bevacizumab has the lowest price, at US\$30-\$75 per dose, when physicians repack it from the original vial into smaller units. However, its off-label status has limited the spread of bevacizumab use. In countries such as People's Republic of China and Japan, doctors are not authorized to prescribe bevacizumab for offlabel use in treating neovascular AMD.

Conbercept (KH902) (Lumitin; Chengdu Kanghong Biotech, Ltd., Sichuan, People's Republic of China) has been tested in a Phase III clinical trial and was approved to treat neovascular AMD by the China State Food and Drug Administration in December 2013. This newest anti-VEGF drug introduced to ophthalmology provides an alternative therapy for retina specialists. Conbercept has not yet reached the market in other countries. However, given its similar structure to aflibercept, excellent safety and efficacy profile, and lower price, conbercept has gained worldwide attention as a promising treatment.

\section{Introduction to conbercept Structure}

To generate a soluble decoy with high affinity to VEGF, drug developers at Chengdu Kanghong Biotech created a series of VEGF receptors by randomly fusing different Ig-like domains of VEGFR-1 or VEGFR-2 to the Fc portion of human IgG1, naming these fusion proteins FP1 to FP6. ${ }^{31}$ A VEGF binding assay and the human umbilical vein endothelial cell (HUVEC) proliferation assay were used for evaluation. FP1 has the same structure as aflibercept and was used as a control. FP3, later named KH902 or conbercept, contains the second Ig-like domain of VEGFR-1 and the third and fourth Ig-like domains of VEGFR-2, was fused to the Fc portion of human IgG1 (shown in Figure 1). ${ }^{32}$ Conbercept has the highest binding affinity to VEGF-A ${ }_{165}(\mathrm{Kd}=0.5 \mathrm{pM})$ and binds all isoforms of VEGF-A, VEGF-B, VEGF-C, and PIGF with high affinity. A comparison of anti-VEGF drugs is shown in Table 1.

Conbercept is a full human DNA sequence engineered protein produced with Chinese hamster ovary cells. This drug binds VEGF dimers in a 1:1 ratio with a "two-fisted grasp" that resembles the activity of aflibercept. The structural difference between these agents is the introduction of extracellular domain 4 of VEGFR-2 to the fused protein. Domain 4 does not participate in ligand binding. However, structure analysis of the ligand-bound VEGFR revealed that domain 4 might be involved in specific homotypic interactions of the ligand-bound receptor, ${ }^{33}$ stabilizing receptor dimers and locking VEGF to the receptor in a rigid manner. ${ }^{34,35}$

Domain 4 ofVEGFR-2 also has a lower isoelectric point(PI). A study has shown that a high positive charge of a fusion protein may lead to poor pharmacokinetic properties. ${ }^{15}$ The addition of domain 4 to conbercept decreases the positive charge of the molecule and may lead to decreased adhesion to the extracellular matrix. The PI of conbercept is 6.13-6.81, ${ }^{36}$ which is lower than the PI of aflibercept (PI 8.82). ${ }^{15}$ The introduction of domain 4 may enhance the association rate of VEGF and prolong the half-life of the drug.

\section{Pharmacokinetics}

Conbercept has a high binding affinity to VEGF-A ${ }_{165}$ $(\mathrm{Kd}=0.5 \mathrm{pM})^{36}$ compared to ranibizumab $(\mathrm{Kd}=46 \mathrm{pM})$ and

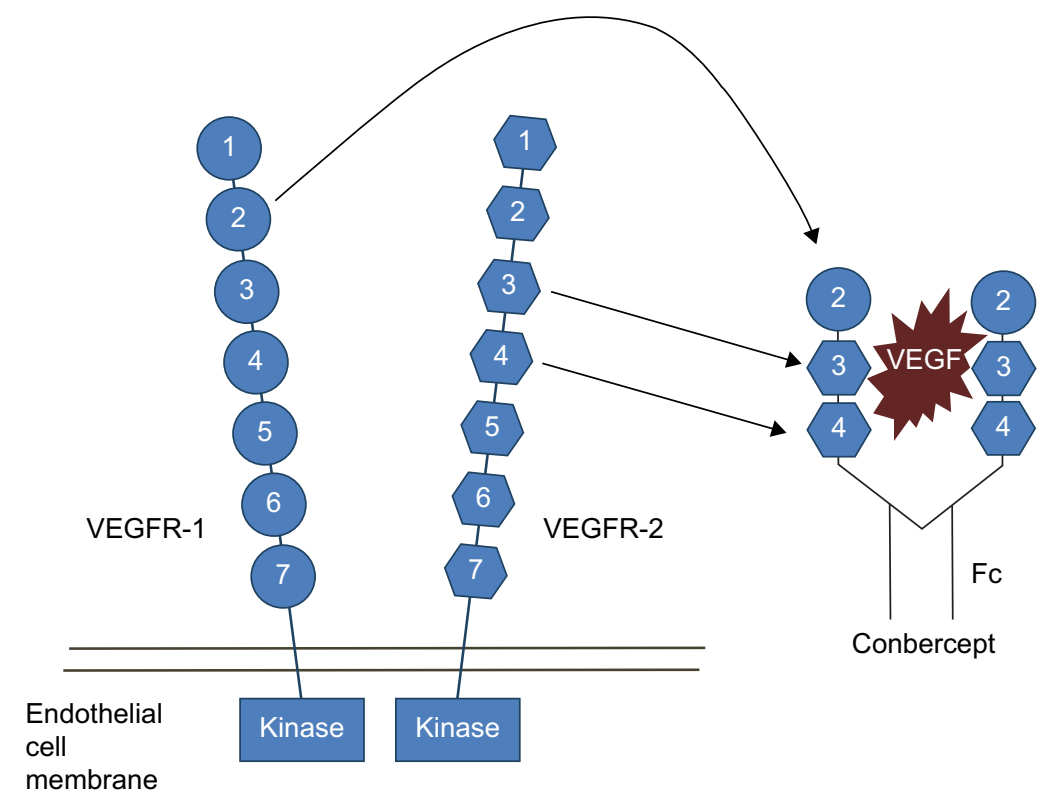

Figure I Conbercept was constructed by fusing the the second Ig-like domain of VEGFR-I and the third and fourth Ig-like domains of VEGFR-2 to the Fc portion of human IgGI. Abbreviations: VEGF, vascular endothelial growth factor; VEGFR, VEGF receptor; Ig, immunoglobulin. 
Table I Comparison of anti-VEGF drugs

\begin{tabular}{|c|c|c|c|c|c|}
\hline & Structure & $\begin{array}{l}\text { Molecular } \\
\text { weight }\end{array}$ & $\begin{array}{l}\text { Mechanism of } \\
\text { action }\end{array}$ & $\begin{array}{l}\text { Binding affinity } \\
\text { to VEGF-A }\end{array}$ & Half-life in vitreous \\
\hline Conbercept & 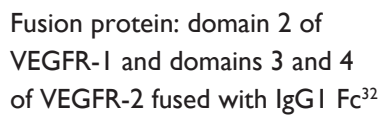 & $143 \mathrm{kDa}^{36}$ & $\begin{array}{l}\text { Binds to all isoforms } \\
\text { of VEGF-A, VEGF-B, } \\
\text { VEGF-C, and PIGF }{ }^{32}\end{array}$ & $0.5 \mathrm{pM}^{36}$ & 4.2 days (in rabbits) ${ }^{38}$ \\
\hline Aflibercept & $\begin{array}{l}\text { Fusion protein: domain } 2 \text { of } \\
\text { VEGFR-I and domain } 3 \text { of } \\
\text { VEGFR-2 fused with } \operatorname{lgG} \mid \mathrm{Fc}^{15}\end{array}$ & II $5 \mathrm{kDa}^{37}$ & $\begin{array}{l}\text { Binds to all isoforms } \\
\text { of VEGF-A, VEGF-B, } \\
\text { and PIGF }{ }^{15}\end{array}$ & $0.5 \mathrm{pM}^{15}$ & $\begin{array}{l}4.79 \text { days } \\
\text { (in rabbits) })^{39}\end{array}$ \\
\hline Ranibizumab & $\begin{array}{l}\text { Monoclonal } \lg G \text { antibody } \\
\text { fragment }(\mathrm{Fab})^{12}\end{array}$ & $48 \mathrm{kDa}^{44}$ & $\begin{array}{l}\text { Binds to all isoforms } \\
\text { of VEGF-A }{ }^{44}\end{array}$ & $46 \mathrm{pM}^{37}$ & $\begin{array}{l}2.88-2.89 \text { days for } 0.5 \mathrm{mg} \text { (in rabbits); }{ }^{44,45} \\
2.63 \text { and } 3.9 \text { days for } 0.5 \mathrm{mg} \text { and } 2 \mathrm{mg} \text {, } \\
\text { respectively (in monkeys) }{ }^{46}\end{array}$ \\
\hline Bevacizumab & Monoclonal IgG antibody ${ }^{40}$ & $149 \mathrm{kDa}^{37}$ & $\begin{array}{l}\text { Binds to all isoforms } \\
\text { of VEGF-A } A^{41}\end{array}$ & $58 \mathrm{pM}^{37}$ & $\begin{array}{l}4.32-6.6 \text { I days for I. } 25 \mathrm{mg} \text { (in rabbits) } ;^{40} \\
6.7 \text { days for I. } 25 \mathrm{mg} \text { (in humans) }\end{array}$ \\
\hline
\end{tabular}

Abbreviations: VEGF, vascular endothelial growth factor; IgG, immunoglobulin G.

bevacizumab $(\mathrm{Kd}=58 \mathrm{pM})$, and its binding affinity is similar to that of aflibercept $(\mathrm{Kd}=0.5 \mathrm{pM}) \cdot{ }^{37}$ Its affinity exceeds even the native VEGF receptor. The high bioactivity of conbercept also relies on its binding affinities to various members of the VEGF family (VEGF-A ${ }_{161}, \mathrm{Kd}=0.5 \mathrm{pM}$; VEGF- ${ }_{167}$, $\mathrm{Kd}=8 \mathrm{pM}$; and PlGF, $\mathrm{Kd}=5 \mathrm{pM}$ ).

The $50 \%$ inhibitory concentration $\left(\mathrm{IC}_{50}\right)$ value of conbercept for $10 \mathrm{pM}$ VEGF-A $\mathrm{A}_{165}$ is $7-15 \mathrm{pM},{ }^{36}$ whereas the $\mathrm{IC}_{50}$ values for ranibizumab and bevacizumab are $343 \mathrm{pM}$ and $423 \mathrm{pM},{ }^{37}$ respectively. The blocking potency of conbercept is similar to that of aflibercept ( $8 \mathrm{pM})$ and 38 - to 48 -fold greater than that of ranibizumab and bevacizumab. Conbercept shows an inhibition effect on VEGF-induced HUVEC proliferation with a $50 \%$ maximal effective concentration $\left(\mathrm{EC}_{50}\right)$ value of $28 \mathrm{pM}$. By contrast, the $\mathrm{EC}_{50}$ for ranibizumab is $50 \mathrm{pM} .{ }^{36}$

\section{Pharmacodynamics}

Conbercept washes out according to first-order kinetics in ocular tissues. The IVT half-life of conbercept is 4.2 days in rabbits. ${ }^{38}$ These data are close to the vitreous half-life of aflibercept (4.79 days) ${ }^{39}$ and bevacizumab (4.3-6.61 days) $)^{40,41}$ in rabbits and longer than that of ranibizumab (2.88 days). The concentrations of conbercept in the rabbit retina and choroid remained higher than the in vitro $\mathrm{IC}_{50}$ value $(7 \mathrm{ng} / \mathrm{g})^{42}$ over 34 days, indicating that a single $0.5 \mathrm{mg}$ IVT injection may have an inhibitory effect against VEGF over the course of 81 days.

In the Phase I clinical trial, the serum concentrations of conbercept in four patients (total number $=6$ ) were undetectable within 1-2 days post-injection, whereas, in two patients, the concentrations were below the lower limit of quantification $(0.195 \mathrm{ng} / \mathrm{mL}){ }^{43}$ In animal experiments, the serum conbercept concentrations after a single dose $(0.5 \mathrm{mg}$ or $1.5 \mathrm{mg})$ of IVT conbercept administration were low and declined to undetectable levels at $8-16$ days after injection. ${ }^{36,38}$
Favorable results were observed in pharmacokinetic and pharmacodynamic studies. Conbercept has a high affinity to all isoforms of VEGF-A as well as to VEGF-B, VEGF-C, and PlGF.

\section{Preclinical studies}

Before clinical trials, conbercept underwent a variety of preclinical studies to test its antiangiogenic effect in vitro and in vivo. Conbercept inhibited VEGF-induced HUVEC migration and tube formation and suppressed the high glucose-induced migration and sprouting of human retinal endothelial cells. ${ }^{42,47}$ In vivo experiments were performed in several ocular neovascular animal models. A single dose of $300 \mu \mathrm{g}$ or $500 \mu \mathrm{g}$ conbercept IVT injection significantly prevented the growth and leakage of experimental monkey CNV induced by perimacular laser photocoagulation. No leakage was observed at 4 weeks. ${ }^{42}$ In experimental diabetic rat models, IVT conbercept improved retinal electrophysiological function and reduced vessel leakage. The therapeutic effects were better than those exhibited by control or bevacizumab-treated rats. ${ }^{48}$ Conbercept significantly reduced the retinal non-perfused area and retinal leakage area in an oxygen-induced retinopathy mouse model. ${ }^{47}$ In an alkali burn-induced mouse corneal neovascularization model, intraperitoneal injection of conbercept also inhibited corneal neovascularization and promoted the regression of established vessels. ${ }^{49}$

In addition to exhibiting efficacy in ophthalmic studies, conbercept decreased tumor growth in several oncology studies, inhibiting tumor growth in human hepatocellular carcinoma (HepG2), ${ }^{50}$ breast cancer (MCF-7), ${ }^{51}$ gastric carcinoma (A549), ${ }^{52}$ and colorectal cancer (LoVo) tumor xenograft models ${ }^{53-55}$ it also reduced the microvessel density in tumor tissues. Conbercept also showed a higher efficacy than bevacizumab in inhibiting tumor growth at the same dose. ${ }^{31}$ 


\section{Clinical trials}

Three clinical trials for treating neovascular AMD with conbercept have been conducted. The Phase I clinical trial was a dose-escalation study of IVT conbercept for neovascular AMD patients. This trial was conducted at the West China Hospital, Chengdu, Sichuan, People's Republic of China. Twenty-eight neovascular AMD patients with primary or recurrent subfoveal CNV and best-corrected VA (BCVA) in the study eye of 55 letters or fewer on the Early Treatment Diabetic Retinopathy chart were enrolled. Six dose levels of conbercept $(0.05,0.15,0.5,1.0,2.0$, and $3.0 \mathrm{mg})$ were investigated. The maximum tolerated dose was reached if more than two patients within a dose group of six patients experienced dose-limiting toxicity within 14 days after conbercept injection.

Patients received an IVT injection of conbercept in the study eye, and follow-up examinations were performed on days 1,3 , $5,7,14,28$, and 42 post-injection. No dose-limiting toxicity was observed up to a dose of $3.0 \mathrm{mg}$. Patients exhibited an average improvement of +19.6 letters in VA without a decline during the 42-day follow-up. Sixteen (57\%) patients improved three lines (15 letters) or more from baseline. In addition, the CRT, measured by optical coherence tomography (OCT), exhibited a mean improvement of $-77.2 \mu \mathrm{m}$ on day 42 . Lesions and CNV evaluated by fluorescein angiography (FA) also improved. Twenty-two (78.5\%) patients had a stable or reduced lesion area, and $18(64.3 \%)$ patients had a stable or reduced CNV area.

This study showed that single IVT injection of conbercept up to $3.0 \mathrm{mg}$ was well tolerated along with vision and anatomic improvements. No significant differences were found among the dose cohorts in terms of VA improvements and CRT.

Based on the results of the Phase I study, the Phase II AURORA study was designed to assess two different doses of conbercept using two dosing regimens. ${ }^{56}$ Treatments and follow-up continued to month 12 . One hundred and twentytwo patients were first randomized into $0.5 \mathrm{mg}$ and $2.0 \mathrm{mg}$ groups and then received three loading doses of monthly IVT conbercept injection. After 3 months, the patients were then randomized into the monthly (Q1M) or PRN group. The mean changes in BCVA from baseline at month 3 were $8.97 \pm 13.08$ letters ( $0.5 \mathrm{mg}$ group) and $10.43 \pm 10.65$ letters ( $2.0 \mathrm{mg}$ group). At month 12, the mean changes in BCVA were 14.31 \pm 17.07 letters $(0.5 \mathrm{mg}$ PRN), $9.31 \pm 10.98$ letters $(0.5 \mathrm{mg} \mathrm{Q} 1 \mathrm{M})$, $12.42 \pm 16.39$ letters ( $2.0 \mathrm{mg} \mathrm{PRN})$, and $15.43 \pm 14.70$ letters (2.0 mg Q1M) compared to baseline. A decline in CRT was also detected in OCT images. By month 12, the mean CRT measurements had decreased by $116.0 \pm 194.84 \mathrm{~mm}(0.5 \mathrm{mg}$
PRN), $131.6 \pm 180.42 \mathrm{~mm}(0.5 \mathrm{mg}$ Q1M), $157.8 \pm 183.98 \mathrm{~mm}$ (2.0 mg PRN), and $168.7 \pm 185.47 \mathrm{~mm}(2.0 \mathrm{mg} \mathrm{Q} 1 \mathrm{M})$. The reductions in the leakage area, $\mathrm{CNV}$ area, and lesion size on FA were significant compared to baseline. At the 12-month follow-up, no significant differences in BCVA or anatomic outcomes were found among the groups, regardless of the doses or dosing regimens. Large-scale clinical trials are needed to further demonstrate the safety and efficacy. The Phase III trial was completed in 2013, and the results were announced at Angiogenesis, Exudation, and Degeneration in 2014.

The Phase III clinical trial was designed in a 2:1 randomization. One hundred and twenty-five patients were enrolled. Patients in the treatment group received three fixed monthly treatments and then two sham injections monthly followed by conbercept injection every 3 months until month 12 (IVT conbercept at months $0,1,2,5,8$, and 11). Patients in the sham injection group were given three monthly sham injections and then crossed over to the treatment group. Both groups had a 12-month follow-up period. The Phase III trial was completed in 2013, and the results were announced at Angiogenesis, Exudation, and Degeneration in 2014. The report from this meeting showed that patients exhibited a mean change in BCVA of +10 letters at month 12. Morphologic changes observed by OCT exhibited a significant reduction in central subfield thickness of $79 \mu \mathrm{m}$ in the treatment groups at month 3 , whereas the sham injection group experienced a decrease of $44 \mu \mathrm{m}$, which was not significant. When the sham injection group was crossed over into the treatment group, similar results were also observed at month 12 on spectral-domain OCT and FA. A reduction in subretinal fluid maximum height at month 3 was seen in the treatment group. After crossing into the treatment group, $93 \%$ of participants had less than $320 \mu \mathrm{m}$ central subfield thickness at month $12 . .^{57,58}$

The three clinical trials of conbercept are summarized in Table 2.

\section{Safety and tolerability}

Conbercept exhibited an excellent safety profile in two published clinical trials. No drug-related intraocular inflammation, endophthalmitis, or systemic serious adverse events (SAEs) were detected in a Phase I trial. Transient elevation in the intraocular pressure (IOP) occurred in all patients after injection, with a mean increase of $10.25 \mathrm{mmHg} 5$ minutes after injection. The IOP dropped to a normal range within 30 minutes except in one patient, whose IOP normalized by day 3. The other adverse event (AE) observed was a single case of subconjunctival hemorrhage (3.6\%). These AEs were all related to the injection procedure rather than the drug itself. 


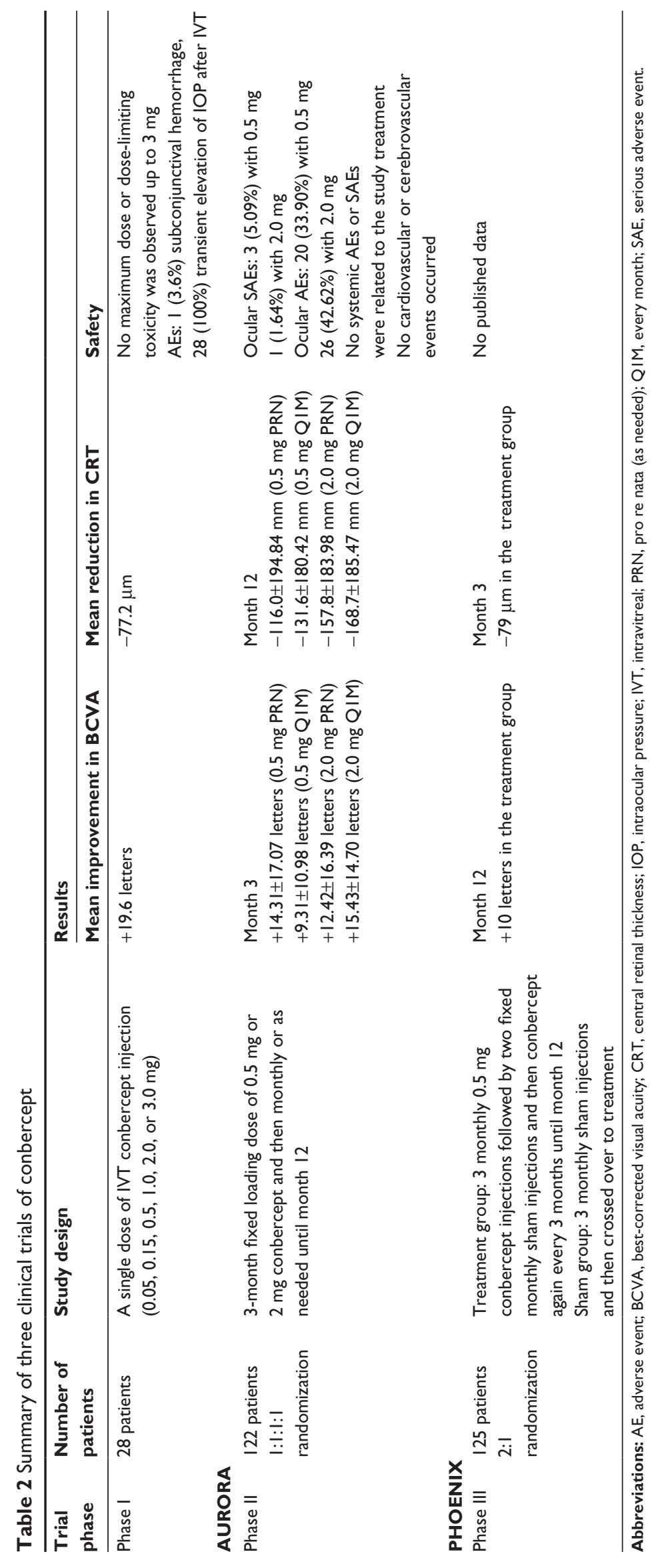


In the Phase II clinical trial, 23 patients (38.89\%) in the $0.5 \mathrm{mg}$ group experienced ocular AEs, including three (5.09\%) SAEs, and 27 patients (44.26\%) in the $2.0 \mathrm{mg}$ group experienced ocular AEs, including one (1.64\%) SAE. Most AEs were mild to moderate and recovered with or without treatment. The most common AE in the two dose groups was conjunctival hemorrhage, affecting seven patients (11.86\%) in the $0.5 \mathrm{mg}$ group and five $(8.2 \%)$ in the $2.0 \mathrm{mg}$ group. Systematic SAEs occurred in seven (11.86\%) patients in the $0.5 \mathrm{mg}$ group and two (3.28) in the $2.0 \mathrm{mg}$ group. None of the systematic SAEs in the two dosing groups were judged to be associated with the drug or study procedure. No cardiovascular or cerebrovascular events, such as heart failure, stroke, or arterial thrombosis, occurred. Due to the limited sample size, the Phase II study was not suitable for assessing the significance of differences in the AEs between the two dose groups. Ocular SAEs in the $0.5 \mathrm{mg}$ group included one case of cataract progression and two cases of reduced VA. Reduced VA was observed in the non-study eye in one patient and the study eye in another patient, and both of these patients exited the trial. Endophthalmitis occurred in one patient (1.64\%) in the $2.0 \mathrm{mg}$ Q1M group; the symptoms resolved after antibiotic treatment, and BCVA had restored to 70 letters at the last visit.

\section{Summary of clinical trials}

All three clinical trials were conducted in People's Republic of China with OCT and FA evaluation by The Digital Angiography Reading Center in Phase II and the Reading Center of the University of Wisconsin in Phase III. Data from clinical trials have demonstrated that conbercept is well tolerated in the eye. The incidence of AEs was low and no higher comparing to other anti-VEGF drugs. No cardiovascular or cerebrovascular events occurred. Neovascular AMD patients treated with conbercept showed an improvement in BCVA comparable to those treated with other anti-VEGF drugs. A similar finding was observed in the reduction of CRT. However, there are limitations to the trials. All of the clinical trials were conducted in People's Republic of China, which means that data on conbercept in Caucasians and Blacks are lacking. The sample sizes of the clinical trials were relatively small, and the follow-up time was only 1 year.

\section{Discussion}

As a new multi-target anti-VEGF drug, conbercept has exhibited excellent therapeutic effects in treating neovascular AMD patients. The induction of domain 4 distinguishes conbercept from aflibercept and enhances the association rate of VEGF to the drug. Due to this structural change, conbercept may pose a longer effect in vitreous. In addition, conbercept had a satisfactory therapeutic effect even with quarterly regimens. However, the results of a Phase III trial are still unpublished; therefore, it is not clear whether a single injection could have a continuous effect that lasts up to the $3 \mathrm{rd}$ month. The trend of BCVA and CRT should be monitored to determine whether there are fluctuations. If such a treatment regime is practical, patients will benefit from receiving fewer injections, reducing the risks associated with injection. A longer continuous efficacy period would also enable patients to attend fewer clinic visits.

For patients who have developed tolerance to the previous anti-VEGF treatment, conbercept appears to be a new therapeutic option. Several studies and clinical trials have demonstrated the efficacy of aflibercept in treating patients who tolerate ranibizumab or bevacizumab, and improvements were observed in both the visual outcome and morphology change in OCT. ${ }^{20,59-61}$ Conbercept is a new multi-target antiVEGF drug with a molecular structure that differs from that of aflibercept. Though it has not been used to treat anti-VEGF-tolerant patients, conbercept is expected to be effective for such patients. Whether the therapeutic effect of conbercept for anti-VEGF drug-tolerant patients is the same as that of aflibercept or altered by the addition of domain 4 merits further investigation.

The effect of conbercept on PCV is also a highlight. The Phase II clinical trial did not exclude patients with PCV, which is assumed to account for up to $50 \%$ of neovascular AMD in People's Republic of China. ${ }^{23}$ The results of the subgroup analysis of PCV are not yet published, but, according to the high prevalence of PCV in People's Republic of China and the visual improvement in the Phase II clinical trial, conbercept may also be an effective treatment for PCV. This possibility parallels the results of studies on aflibercept in PCV patients. ${ }^{62,63}$ IVT administration of aflibercept has a significant effect on polypoidal lesions, and the rates of lesion reduction might compare to those achieved with the combination of PDT and ranibizumab. As conbercept and aflibercept work in a similar manner, promising visual and morphologic outcomes are expected for conbercept. An ongoing Phase IV clinical trial of conbercept for the treatment of PCV will provide more information in the future.

In the real world, the cost of anti-VEGF drugs affects physicians' and patients' use of these agents. The high price and potentially higher number of injections of ranibizumab are also burdens on the medical insurance system. A switch to a cheaper but equally effective alternative would be beneficial. In countries where all anti-VEGF drugs are available, 
bevacizumab may be preferred over others because of its equivalent efficacy and safety combined with a lower price. ${ }^{30}$ However, its off-label status has limited the use of bevacizumab, and there is concern about sterility with repacking. Conbercept $(6,800$ RMB [US\$1,108] in People's Republic of China) is approximately $60 \%$ the price of ranibizumab and aflibercept in the United States. When following the recommended treatment regimens after three loading doses, which is monthly for ranibizumab and quarterly for conbercept, the total expense in the 1st year of treatment would be reduced by up to $70 \%$ when using conbercept. As anti-VEGF therapy for neovascular AMD requires a long treatment course, the savings will accumulate. In countries where anti-VEGF drugs are covered by medical insurance, a lower price decreases the burden on medical insurance. Anti-VEGF treatments are costly in places where anti-VEGF drugs are not covered by medical insurance and the use of bevacizumab for neovascular AMD is prohibited due to legal provisions. Because conbercept was approved by the China State Food and Drug Administration, retina specialists are free to prescribe it.

Conbercept has only been used in clinical practice for 1 year. Although it has shown promising therapeutic effect in treating neovascular AMD patients, more studies and clinical trials are needed to explore its full potential, especially in people of different races. Head-to-head studies are warranted to compare conbercept with other anti-VEGF drugs and further validate its safety and efficacy in treating neovascular AMD as well as PCV.

\section{Acknowledgments}

This study is supported by grants from the National Science Foundation for Distinguished Young Scholars (81425006), National Basic Research Program of China 973 Program (2011CB707506), the National Natural Science Foundation of China (81271030), and Shanghai Creative Key Medical Research (1341195400).

\section{Disclosure}

Dr Sun is a consultant to Novartis and Chengdu Kanghong Biotech. The authors report no other conflicts of interest in this work. This review received no specific grant from any funding agency in the public, commercial, or not-for-profit sectors.

\section{References}

1. Friedman DS, O’Colmain BJ, Muñoz B, et al; Eye Diseases Prevalence Research Group. Prevalence of age-related macular degeneration in the United States. Arch Ophthalmol. 2004;122(4):564-572.

2. Ferris FL 3rd, Fine SL, Hyman L. Age-related macular degeneration and blindness due to neovascular maculopathy. Arch Ophthalmol. 1984;102(11):1640-1642.
3. Spilsbury K, Garrett KL, Shen WY, Constable IJ, Rakoczy PE. Overexpression of vascular endothelial growth factor (VEGF) in the retinal pigment epithelium leads to the development of choroidal neovascularization. Am J Pathol. 2000;157(1):135-144.

4. Ishibashi T, Hata Y, Yoshikawa H, Nakagawa K, Sueishi K, Inomata H. Expression of vascular endothelial growth factor in experimental choroidal neovascularization. Graefes Arch Clin Exp Ophthalmol. 1997;235(3):159-167.

5. Sloan FA, Hanrahan BW. The effects of technological advances on outcomes for elderly persons with exudative age-related macular degeneration. JAMA Ophthalmol. 2014;132(4):456-463.

6. Bloch SB, Larsen M, Munch IC. Incidence of legal blindness from age-related macular degeneration in denmark: year 2000 to 2010. Am J Ophthalmol. 2012;153(2):209-213.e2.

7. Skaat A, Chetrit A, Belkin M, Kinori M, Kalter-Leibovici O. Time trends in the incidence and causes of blindness in Israel. $A m J$ Ophthalmol. 2012;153(2):214-221.e1.

8. Gragoudas ES, Adamis AP, Cunningham ET Jr, Feinsod M, Guyer DR; VEGF Inhibition Study in Ocular Neovascularization Clinical Trial Group. Pegaptanib for neovascular age-related macular degeneration. N Engl J Med. 2004;351(27):2805-2816.

9. Macugen AMD Study Group, Apte RS, Modi M, et al. Pegaptanib 1-year systemic safety results from a safety-pharmacokinetic trial in patients with neovascular age-related macular degeneration. Ophthalmology. 2007;114(9):1702-1712.

10. Ferrara N, Damico L, Shams N, Lowman H, Kim R. Development of ranibizumab, an anti-vascular endothelial growth factor antigen binding fragment, as therapy for neovascular age-related macular degeneration. Retina. 2006;26(8):859-870.

11. CATT Research Group, Martin DF, Maguire MG, et al. Ranibizumab and bevacizumab for neovascular age-related macular degeneration. N Engl J Med. 2011;364(20):1897-1908.

12. Rosenfeld PJ, Brown DM, Heier JS, et al; MARINA Study Group. Ranibizumab for neovascular age-related macular degeneration. $N$ Engl $J$ Med. 2006;355(14):1419-1431.

13. Comparison of Age-related Macular Degeneration Treatments Trials (CATT) Research Group, Martin DF, Maguire MG, et al. Ranibizumab and bevacizumab for treatment of neovascular agerelated macular degeneration: two-year results. Ophthalmology. 2012;119(7):1388-1398.

14. IVAN Study Investigators, Chakravarthy U, Harding SP, et al. Ranibizumab versus bevacizumab to treat neovascular age-related macular degeneration: one-year findings from the IVAN randomized trial. Ophthalmology. 2012;119(7):1399-1411.

15. Holash J, Davis S, Papadopoulos N, et al. VEGF-Trap: a VEGF blocker with potent antitumor effects. Proc Natl Acad Sci U S A. 2002; 99(17):11393-11398.

16. Schaal S, Kaplan HJ, Tezel TH. Is there tachyphylaxis to intravitreal anti-vascular endothelial growth factor pharmacotherapy in age-related macular degeneration? Ophthalmology. 2008;115(12):2199-2205.

17. Forooghian F, Cukras C, Meyerle CB, Chew EY, Wong WT. Tachyphylaxis after intravitreal bevacizumab for exudative age-related macular degeneration. Retina. 2009;29(6):723-731.

18. Eghøj MS, Sørensen TL. Tachyphylaxis during treatment of exudative age-related macular degeneration with ranibizumab. Br J Ophthalmol. 2012;96(1):21-23.

19. Gasperini JL, Fawzi AA, Khondkaryan A, et al. Bevacizumab and ranibizumab tachyphylaxis in the treatment of choroidal neovascularisation. Br J Ophthalmol. 2012;96(1):14-20.

20. Bakall B, Folk JC, Boldt HC, et al. Aflibercept therapy for exudative age-related macular degeneration resistant to bevacizumab and ranibizumab. Am J Ophthalmol. 2013;156(1):15-22.e1.

21. Yannuzzi LA, Sorenson J, Spaide RF, Lipson B. Idiopathic polypoidal choroidal vasculopathy (IPCV). 1990. Retina. 2012;32 Suppl 1:1-8.

22. Khetan V, Shanmugam MP, Bhende MP, Shetty NS. Polypoidal choroidal vasculopathy. Surv Ophthalmol. 2004;49(6):620-621; author reply 621. 
23. Liu Y, Wen F, Huang S, et al. Subtype lesions of neovascular agerelated macular degeneration in Chinese patients. Graefes Arch Clin Exp Ophthalmol. 2007;245(10):1441-1445.

24. Byeon SH, Lee SC, Oh HS, Kim SS, Koh HJ, Kwon OW. Incidence and clinical patterns of polypoidal choroidal vasculopathy in Korean patients. Jpn J Ophthalmol. 2008;52(1):57-62.

25. Sho K, Takahashi K, Yamada H, et al. Polypoidal choroidal vasculopathy: incidence, demographic features, and clinical characteristics. Arch Ophthalmol. 2003;121(10):1392-1396.

26. Kang HM, Koh HJ. Long-term visual outcome and prognostic factors after intravitreal ranibizumab injections for polypoidal choroidal vasculopathy. Am J Ophthalmol. 2013;156(4):652-660.

27. Hikichi T, Higuchi M, Matsushita T, et al. One-year results of three monthly ranibizumab injections and as-needed reinjections for polypoidal choroidal vasculopathy in Japanese patients. Am J Ophthalmol. 2012;154(1):117-124.e1.

28. Wakabayashi T, Gomi F, Sawa M, Tsujikawa M, Nishida K. Intravitreal bevacizumab for exudative branching vascular networks in polypoidal choroidal vasculopathy. Br J Ophthalmol. 2012;96(3):394-399.

29. Syed BA, Evans JB, Bielory L. Wet AMD market. Nat Rev Drug Discov. 2012;11(11):827.

30. Brechner RJ, Rosenfeld PJ, Babish JD, Caplan S. Pharmacotherapy for neovascular age-related macular degeneration: an analysis of the 100\% 2008 medicare fee-for-service part B claims file. Am J Ophthalmol. 2011;151(5):887-895.e1.

31. Yu DC, Lee JS, Yoo JY, et al. Soluble vascular endothelial growth factor decoy receptor FP3 exerts potent antiangiogenic effects. Mol Ther. 2012;20(5):938-947.

32. Wu Z, Zhou P, Li X, et al. Structural characterization of a recombinant fusion protein by instrumental analysis and molecular modeling. PLoS One. 2013;8(3):e57642.

33. Kisko K, Brozzo MS, Missimer J, et al. Structural analysis of vascular endothelial growth factor receptor-2/ligand complexes by small-angle X-ray solution scattering. FASEB J. 2011;25(9):2980-2986.

34. Shinkai A, Ito M, Anazawa H, Yamaguchi S, Shitara K, Shibuya M. Mapping of the sites involved in ligand association and dissociation at the extracellular domain of the kinase insert domain-containing receptor for vascular endothelial growth factor. $J$ Biol Chem. 1998;273(47):31283-31288.

35. Fuh G, Li B, Crowley C, Cunningham B, Wells JA. Requirements for binding and signaling of the kinase domain receptor for vascular endothelial growth factor. J Biol Chem. 1998;273(18):11197-11204.

36. Zhang M, Yu D, Yang C, et al. The pharmacology study of a new recombinant human VEGF receptor-fc fusion protein on experimental choroidal neovascularization. Pharm Res. 2009;26(1):204-210.

37. Papadopoulos N, Martin J, Ruan Q, et al. Binding and neutralization of vascular endothelial growth factor (VEGF) and related ligands by VEGF Trap, ranibizumab and bevacizumab. Angiogenesis. 2012; 15(2):171-185.

38. Li H, Lei N, Zhang M, Li Y, Xiao H, Hao X. Pharmacokinetics of a long-lasting anti-VEGF fusion protein in rabbit. Exp Eye Res. 2012;97(1):154-159.

39. Stewart MW, Rosenfeld PJ. Predicted biological activity of intravitreal VEGF Trap. Br J Ophthalmol. 2008;92(5):667-668.

40. Sinapis CI, Routsias JG, Sinapis AI, et al. Pharmacokinetics of intravitreal bevacizumab (Avastin ${ }^{\circledR}$ ) in rabbits. Clin Ophthalmol. 2011;5:697-704.

41. Bakri SJ, Snyder MR, Reid JM, Pulido JS, Singh RJ. Pharmacokinetics of intravitreal bevacizumab (Avastin). Ophthalmology 2007;114(5):855-859.

42. Zhang M, Zhang J, Yan M, Li H, Yang C, Yu D. Recombinant antivascular endothelial growth factor fusion protein efficiently suppresses choridal neovasularization in monkeys. Mol Vis. 2008;14:37-49.

43. Zhang M, Zhang J, Yan M, et al; KH902 Phase 1 Study Group. A phase 1 study of KH902, a vascular endothelial growth factor receptor decoy, for exudative age-related macular degeneration. Ophthalmology. 2011;118(4):672-678.
44. Bakri SJ, Snyder MR, Reid JM, Pulido JS, Ezzat MK, Singh RJ. Pharmacokinetics of intravitreal ranibizumab (Lucentis). Ophthalmology. 2007;114(12):2179-2182.

45. Gaudreault J, Fei D, Beyer JC, et al. Pharmacokinetics and retinal distribution of ranibizumab, a humanized antibody fragment directed against VEGF-A, following intravitreal administration in rabbits. Retina. 2007;27(9):1260-1266.

46. Gaudreault J, Fei D, Rusit J, Suboc P, Shiu V. Preclinical pharmacokinetics of Ranibizumab (rhuFabV2) after a single intravitreal administration. Invest Ophthalmol Vis Sci. 2005;46(2):726-733.

47. Wang F, Bai Y, Yu W, et al. Anti-angiogenic effect of KH902 on retinal neovascularization. Graefes Arch Clin Exp Ophthalmol. 2013; 251(9):2131-2139.

48. Huang J, Li X, Li M, et al. Effects of intravitreal injection of KH902, a vascular endothelial growth factor receptor decoy, on the retinas of streptozotocin-induced diabetic rats. Diabetes Obes Metab. 2012;14(7): 644-653.

49. Zhou AY, Bai YJ, Zhao M, Yu WZ, Li XX. KH902, a recombinant human VEGF receptor fusion protein, reduced the level of placental growth factor in alkali burn induced-corneal neovascularization. Ophthalmic Res. 2013;50(3):180-186.

50. Gao W, Jin K, Lan H, Han N, Cao F, Teng L. FP3: a novel VEGF blocker with anti-angiogenic and anti-tumor effects. Hepatogastroenterology. 2012;59(120):2543-2547.

51. Lan H, Zheng L, Jin K, Teng L. Antitumor effect of FP3 in a breast cancer xenograft model. Exp Ther Med. 2013;5(1):85-88.

52. Jin K, Lan H, Cao F, et al. Antitumor effect of FP3 in a patient-derived tumor tissue xenograft model of gastric carcinoma through an antiangiogenic mechanism. Oncol Lett. 2012;3(5):1052-1058.

53. Dong X, Jin K, Hu X, et al. Antitumor effect of FP3 in combination with cetuximab on patient-derived tumor tissue xenograft models of primary colon carcinoma and related lymphatic and hepatic metastases. Int J Mol Med. 2012;30(1):126-132.

54. Jin K, Li G, Cui B, et al. Assessment of a novel VEGF targeted agent using patient-derived tumor tissue xenograft models of colon carcinoma with lymphatic and hepatic metastases. PLoS One. 2011;6(12):e28384.

55. Bi T, Bi T, Lan H, et al. Antitumor effect of FP3 on a patient-derived tumor tissue xenograft model of rectal carcinoma. Hepatogastroenterology. 2013;60(128):1950-1954.

56. Li X, Xu G, Wang Y, et al; AURORA Study Group. Safety and efficacy of conbercept in neovascular age-related macular degeneration: results from a 12-month randomized phase 2 study: AURORA study. Ophthalmology. 2014;121(9):1740-1747.

57. Kaiser P. Anti-VEGF Therapy in Wet AMD and Conbercept Development. Report presented at: Angiogenesis, Exudation, and Degeneration; February 8, 2014; Miami, FL, USA.

58. Danis P. Imaging Data From the Phase 3 Clinical Trial of Conbercept in Neovascular AMD. Report presented at: Angiogenesis, Exudation, and Degeneration; February 8, 2014; Miami, FL, USA.

59. Cho H, Shah CP, Weber M, Heier JS. Aflibercept for exudative AMD with persistent fluid on ranibizumab and/or bevacizumab. $B r J$ Ophthalmol. 2013;97(8):1032-1035.

60. Wykoff CC, Brown DM, Maldonado ME, Croft DE. Aflibercept treatment for patients with exudative age-related macular degeneration who were incomplete responders to multiple ranibizumab injections (TURF trial). Br J Ophthalmol. 2014;98(7):951-955.

61. Heussen FM, Shao Q, Ouyang Y, Joussen AM, Müller B. Clinical outcomes after switching treatment from intravitreal ranibizumab to aflibercept in neovascular age-related macular degeneration. Graefes Arch Clin Exp Ophthalmol. 2014;252(6):909-915.

62. Ijiri S, Sugiyama K. Short-term efficacy of intravitreal aflibercept for patients with treatment-naïve polypoidal choroidal vasculopathy. Graefes Arch Clin Exp Ophthalmol. Epub 2014 Jul 13.

63. Inoue M, Arakawa A, Yamane S, Kadonosono K. Short-term efficacy of intravitreal aflibercept in treatment-naive patients with polypoidal choroidal vasculopathy. Retina. 2014;34(11):2178-2184. 


\section{Publish your work in this journal}

Drug Design, Development and Therapy is an international, peerreviewed open-access journal that spans the spectrum of drug design and development through to clinical applications. Clinical outcomes, patient safety, and programs for the development and effective, safe, and sustained use of medicines are a feature of the journal, which

has also been accepted for indexing on PubMed Central. The manuscript management system is completely online and includes a very quick and fair peer-review system, which is all easy to use. Visit http://www.dovepress.com/testimonials.php to read real quotes from published authors.

Submit your manuscript here: http://www.dovepress.com/drug-design-development-and-therapy-journal 